Research Article

\title{
Graphite Intended for Green Engineering Developed by Noncontaminant Reverse Abrasion
}

\author{
Roberto Baca Arroyo \\ Department of Electronics, National Polytechnic Institute, 07738 Mexico City, DF, Mexico \\ Correspondence should be addressed to Roberto Baca Arroyo; rbaca02006@yahoo.com.mx
}

Received 13 January 2016; Revised 2 April 2016; Accepted 14 April 2016

Academic Editor: Jianxi Zhu

Copyright ( 2016 Roberto Baca Arroyo. This is an open access article distributed under the Creative Commons Attribution License, which permits unrestricted use, distribution, and reproduction in any medium, provided the original work is properly cited.

Graphite intended for green engineering was synthesized by noncontaminant reverse abrasion, which consists of graphite layers assembled with thickness controlled on $\mathrm{SiC}$ sandpaper as insulating substrate. Phase formation of the graphite layers was validated by X-ray diffraction studies and its finished profile by Atomic Force Microscopy (AFM). Transport parameters of only three layers were evaluated from current-voltage curves. Mathematical functions such as derivative and modulation of a signal have been built by graphite circuits using different performance principles, compared to those used with silicon devices. The trends related to electronic engineering should be achieved with design of the graphite-based devices to facilitate their mass production in the near future.

\section{Introduction}

In the last decades, advances in electronic engineering based on circuits of large scale integration (LSI) have found extensive application in communications, automation, and other areas [1]. However, such applications have been implemented by silicon-based architectures and their end life corresponding to the waste electronics which deteriorate the environment at high levels of pollution. By using different performance principles as well as employing earth materials [2], carbon-based architectures intended from elementary mathematical functions could satisfy environmental requirements to the fabrication of novel applications such as control devices and sensors [3-5].

Researchers have synthesized carbon-based devices using chemical vapor deposition (CVD) techniques where volatile compounds of carbon onto nickel or cooper surfaces serve to catalyze the conversion of those into graphene by epitaxial growth and annealing of silicon carbide $(\mathrm{SiC})$ at high temperatures $[6,7]$. Due to that high cost of production, setback in its scalability, degradation of electronic properties, requirement of specialized equipment, poor mass production, and environmental concerns related to the toxic vapors, the market for carbon-based devices has been blocked. It is known that excessive levels of carbon gases can exacerbate biological effects with accumulative damage in the health $[8,9]$.

Graphite is an allotrope of carbon which is the most stable under standard conditions and has been widely recycled from synthetic graphite electrodes of zinc-carbon batteries and electric motor brushes and others [10]. It is difficult for the ignition of the graphite to occur as a result of its higher thermal conductivity of $k=2000 \mathrm{Wm} / \mathrm{K}$ and electron delocalization within its carbon layers as well as thermal properties highly anisotropic [11], since phonons propagate very quickly along its bound planes but slower for traveling from one plane to another [12]. Ambipolarity phenomena could be a disadvantage to design semiconductor devices by its pure state with a zero-band gap which imply that for both positive and negative bias voltage any current flow does not change, but motion of the charge carries and heat conduction depend on its thickness and dimensions, which can be an advantage for graphite-based devices $[7,13]$.

Alternatively, an abrasive material as $\mathrm{SiC}$ has several advantages to be functional under extreme conditions without breakdown damage. It is well known that $\mathrm{SiC}$ substrate is very expensive, but it has higher thermal conductivity of $k=100-350 \mathrm{Wm} / \mathrm{K}$ at room temperature. Therefore, $\mathrm{SiC}$ sandpaper can be used as an insulating substrate, being easily 


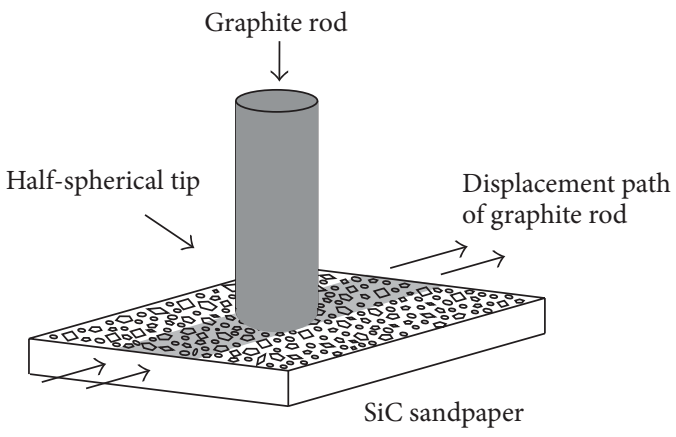

(a)
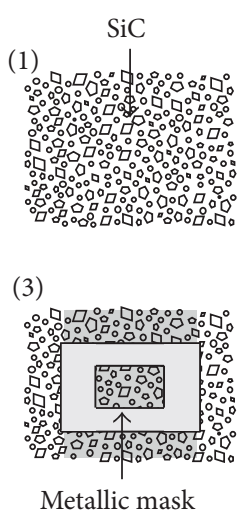

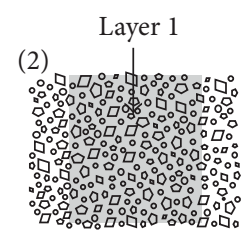

(4)

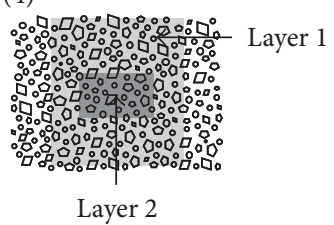

(b)

FIgURE 1: (a) Schematic of the reverse abrasion technique. (b) Four steps employed for assembling of the graphite layers.

found on the market at low cost. When it is used as substrate, it must be selected by its grain size and area to get finer finished profiles $[13,14]$.

This work introduces the fabrication of graphite layers made by noncontaminant reverse abrasion technique. Details of this process are presented in Section 2. Structural and transport parameters of the graphite layers as well as examples of green engineering are covered in Section 3. Finally, conclusions about this research are available in Section 4.

\section{Material and Methods}

Graphite rods with radii of $1 \mathrm{~mm}$ were recuperated from old pencils into their final stage, which can be used to be assembled on $\mathrm{SiC}$ sandpaper by friction forces between finer abrasive particles of $\mathrm{SiC}$ and graphite atoms to control the amount of graphite assembled on $\mathrm{SiC}$ substrate. To know the stability of the assembling, it is explained based on insertion of graphite atoms between layers and their stacking profile in $\mathrm{SiC}$ sandpaper which is related to the nucleation phenomena by stronger attractive forces between graphite and $\mathrm{SiC}$ atoms at the interface [9].

Figure 1(a) shows the schematic of the process where a graphite rod with a half-spherical tip must be continuously displaced on a $\mathrm{SiC}$ surface. Figure 1(b) indicates the four steps for synthesizing of the graphite layers. At the beginning the needed area of $\mathrm{SiC}$ sandpaper must be cut off with scissors (step 1). After that, a first graphite layer of smaller thickness can be assembled on $\mathrm{SiC}$ sandpaper (step 2). A metallic mask of $1.5 \times 1.5 \mathrm{~mm}^{2}$, for example, should be placed after (step 3) as pattern of the junction area. Finally, a second layer of greater thickness can be assembled (step 4).

Phase formation of the graphite layers is validated by $\mathrm{X}$ ray diffraction studies (XRD patterns) with a PANalytical diffractometer of $\mathrm{CuK}_{\alpha}$ radiation $(\lambda=0.15418 \mathrm{~nm})$. Finished profiles of the graphite surface as a function of asperities density and height distribution are studied by Atomic Force Microscopy (AFM) using a Digital Instrument (Veeco) Nanoscope. Transport of the graphite layers is evaluated from current-voltage curves. Graphite circuits are fabricated to demonstrate green engineering and its behavior is confirmed by waveforms collected with a digital storage oscilloscope (Tektronix, TDS1012C).

\section{Results and Discussion}

Pencils are still a small but significant source of natural graphite with planar structure of hexagonal form which can be useful by its mechanical properties based on easier slide of either smooth or distorted layers one to the other on $\mathrm{SiC}$ sandpaper. For that reason, to satisfy the trends related to electronic engineering of large scale integration (LSI), graphite and $\mathrm{SiC}$ are excellent candidates and only three types of graphite layers are synthesized by using the procedure of Figure 1.

3.1. Structural and Transport Parameters of Graphite Layers. Figure 2 shows XRD patterns of the layers synthesized. Samples labeled as GF1, GF2, and GF3 exhibit hexagonal phase of graphite with peak located at $26.60^{\circ}$ and plane (002) according to PANalytical Card number 00-025-0284 and other authors $[15,16]$. XRD pattern of the SiC substrate is labeled by the $\mathrm{SiC}$ sandpaper as reference. Additional peaks are corresponding with $\mathrm{SiC}$, the highest peak being at $35.60^{\circ}$ with (111) plane associated with cubic phase, according to PANalytical Card number 00-029-1127, while those peaks positioned at $34.70^{\circ}, 38.02^{\circ}, 60.05^{\circ}, 65.60^{\circ}$, and $71.80^{\circ}$ with (101), (102), (110), (106), and (114) planes correspond to hexagonal phase according to PANalytical Card number 00-029-1129. XRD patterns indicate that the peaks heights corresponding to $\mathrm{SiC}$ substrate decrease, when hexagonal phase of graphite increases as a function of the assembling on $\mathrm{SiC}$ sandpaper.

Surface color of each layer assembled on $\mathrm{SiC}$ sandpaper is a first evidence of its finished profile. Nevertheless, a statistical behavior of the graphite surface allows knowing characteristics such as asperity which can be measured by $R_{a}$ parameter as the variation in profile height (roughness average), and average thickness as a function of the $R_{P}$ parameter can be analyzed to demonstrate the amount of graphite assembled (surface texture). Therefore, using an AFM analysis the finished profile of the graphite surface can be understood. 


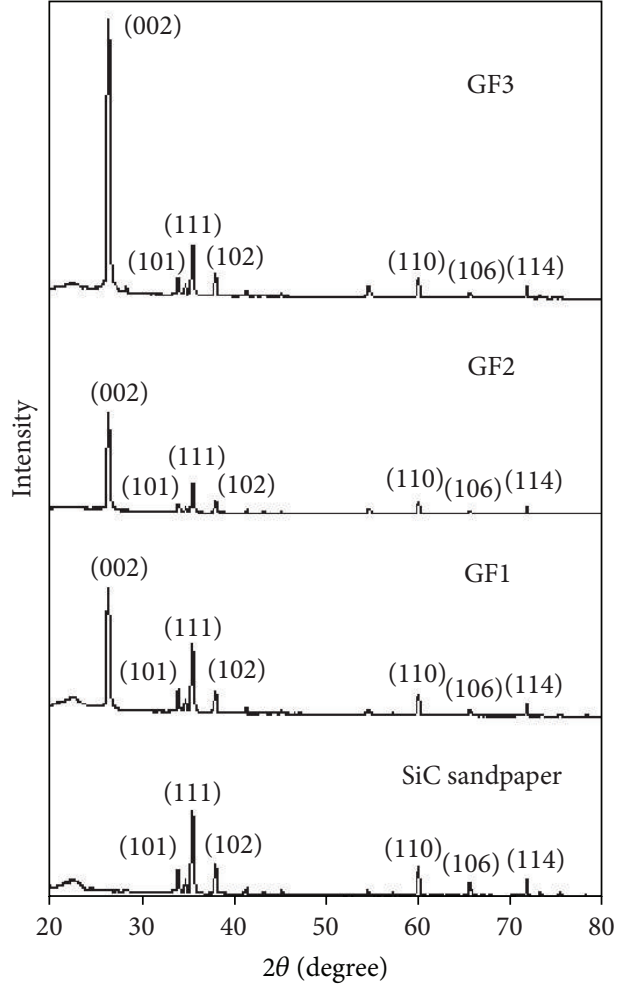

FIGURE 2: XRD patterns of graphite layers as a function of the amount of the graphite assembled on $\mathrm{SiC}$ sandpaper as substrate.

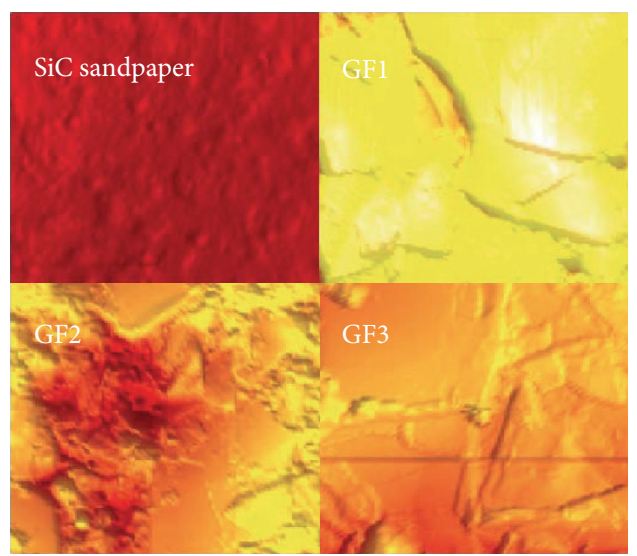

FIGURE 3: AFM images of samples with graphite assembled of different thickness. As reference, the AFM image of $\mathrm{SiC}$ sandpaper is shown.

Figure 3 shows AFM images of well-known samples labeled as $\mathrm{SiC}$ sandpaper, GF1, GF2, and GF3.

It is well known that a rough surface has the capacity to abrade, if its asperities induce stresses; thus the graphite surface should be measured as a function of density of the asperities and height distribution [14, 17]. Roughness and thickness average as finished parameters are related to the amount of graphite assembled and friction forces involved, which can be studied by a roughness algorithm using the
TABLE 1: Finished parameters from graphite samples.

\begin{tabular}{|c|c|c|c|c|}
\hline Parameter & $\begin{array}{c}\mathrm{SiC} \\
\text { sandpaper }\end{array}$ & GF1 & GF2 & GF3 \\
\hline Surface color & Water & $\begin{array}{l}\text { Dark } \\
\text { gray }\end{array}$ & $\begin{array}{c}\text { Opaque } \\
\text { gray }\end{array}$ & Gray \\
\hline $\begin{array}{l}\text { Scanned area } \\
\left(\mu \mathrm{m}^{2}\right)\end{array}$ & 1.08 & 1.09 & 1.10 & 1.15 \\
\hline$R_{a}(\mathrm{~nm})$ & 2.13 & 15.30 & 10.32 & 15.70 \\
\hline$R_{p}(\mathrm{~nm})$ & 240.20 & 309.80 & 416.20 & 831.20 \\
\hline
\end{tabular}

TABLE 2: Transport parameters from graphite layers.

\begin{tabular}{lcccc}
\hline Sample & $S\left(\mathrm{~cm}^{2}\right)$ & $d V / d I(\mathrm{k} \Omega)$ & $\sigma\left(\Omega^{-1} \mathrm{~cm}^{-1}\right)$ & $\mu_{n}\left(\mathrm{~cm}^{2} \mathrm{~V}^{-1} \mathrm{~s}^{-1}\right)$ \\
\hline GF1 & $4.64 \times 10^{-4}$ & 22.72 & 0.057 & 255.40 \\
GF2 & $6.24 \times 10^{-4}$ & 8.33 & 0.115 & 289.60 \\
GF3 & $12.46 \times 10^{-4}$ & 4.54 & 0.106 & 285.40 \\
\hline
\end{tabular}

Veeco software. Such finished parameters are listed in Table 1. It is confirmed that the graphite samples assembled on $\mathrm{SiC}$ sandpaper have different finished profiles with $R_{a}$ parameter in the range from 2 to $16 \mathrm{~nm}$, lower than its carrier mean free path of $l=235 \mathrm{~nm}$ which is a critical parameter for electronic transport in graphite devices $[7,12]$.

To know the electronic transport of the graphite layers, an electrical circuit of Figure 4(a) has been built to obtain current-voltage curves of well-known samples labeled GF1, GF2, and GF3. Sinusoidal signal must be applied as input voltage and a resistor of $100 \Omega$ for monitoring of the output signal was used. Physical diagram of Figure 4(b) was built for measuring of each layer, where two aluminum (Al) electrodes were placed to connect the graphite layer of $l_{s}=6 \mathrm{~mm}$ of length. Figure 4(c) shows that each curve had an ohmic behavior from -10 to $10 \mathrm{~V}$ which has been previously studied by Ohm's law $d V / d I=l_{s} / \sigma S$ [12]. From the slope $d V / d I$ of each curve, the conductivity $\sigma$ as a function of $l_{s}$, and crosssectional area, $S$ equal to the multiplication between layer thickness and metallic mask wide can be computed.

Because low-field regime $\left(F<10^{6} \mathrm{Vcm}^{-1}\right)$ is dominated by thermal scattering of phonons and thermal velocity $v_{T}=\mu_{n} F$ is linear in field [18], the average drift mobility, $\mu_{n}$ in graphite as a function of the variation of dimensions, thickness, and lower number of defects gives an indication on stability of the electronic transport. Consequently, $\mu_{n}$ should be calculated as a function of the thickness, which is equivalent to the $R_{P}$ parameter from AFM analysis (see Table 1) and can be described by $\mu_{n}=R_{p} v_{T} / V$ with $v_{T}=4.8 \times 10^{7} \mathrm{~cm} / \mathrm{s}$ for graphite and $V$ as bias voltage across the layers.

Table 2 gives the transport parameters from the experiment conducted in Figure 4. Current-voltage curves allow knowing that the ambipolar behavior of graphite is dependent on $\mu_{n}$ and $\sigma$ which can be controlled by device geometry, such as thickness and electrode dimensions, to get stable electronic transport.

3.2. Green Engineering Based on Graphite Circuits. To demonstrate that derivative of a signal based on current injection 


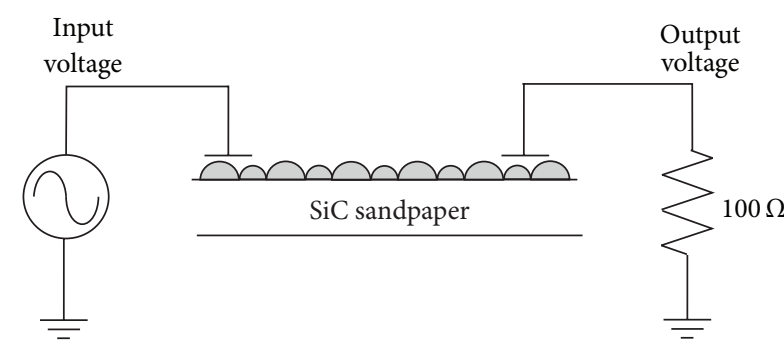

(a)

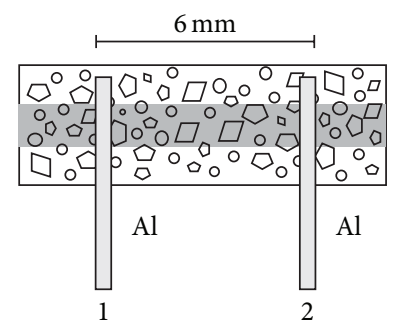

(b)

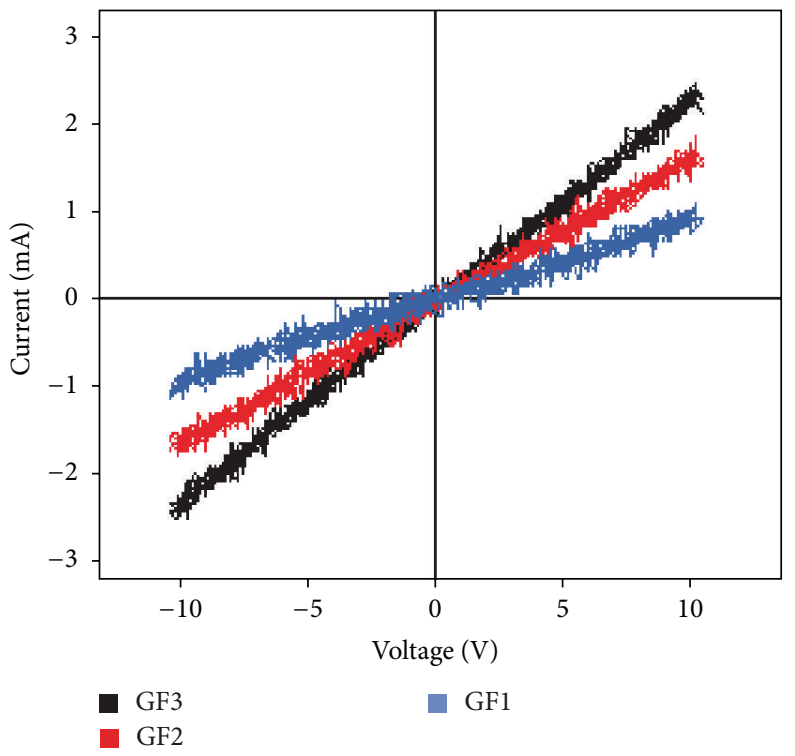

(c)

Figure 4: (a) Practical circuit implemented. (b) Physical diagram of the experimental procedure. (c) Current-voltage curves.

by a bias voltage can be developed, a schematic diagram of a graphite layer assembled as circuit is shown in Figure 5(a), which consists of the following array: a capacitor connected in series to a first section of the graphite layer with $3 \mathrm{~mm}$ of length located between electrodes 1 and 2 to perform a RC circuit, while, between electrodes 1 and 3 , a second section with similar length to the first section is used to provide the bias voltage.

It is well known that a typical response of a RC circuit is equivalent to the differentiator circuit [19], but when an additional element is added a special behavior for the RC circuit can be gotten. Figure 5(b) shows a block diagram of the Pulse Width Modulation (PWM) which could be easier implemented by using of the circuit of Figure 5(a), simplifying the well-known silicon-based circuits traditionally fabricated by complex-signal processors [20, 21]. By applying a square signal as input voltage of amplitude $1 \mathrm{~V}$, duty cycle of $30 \%$, and frequency of $100 \mathrm{~Hz}$, the performance of the circuit of Figure 5 can be demonstrated. Figure 5(c) indicates typical derivative of a signal with a slope increased when bias voltage was not applied, while that derivative of a signal with slope decreased under bias voltage of $5 \mathrm{~V}$ can be driven (see Figure $5(\mathrm{~d})$ ). As a result, if a bias voltage in the range from 0 to $5 \mathrm{~V}$ is injected, gradual slope changes can be obtained.
To disclose that a graphite circuit can be used for modulation of signals, a schematic diagram of Figure 6(a) should be realized with two graphite layers of different conductivity GF1 and GF3 (see Table 2). The behavior of this modulator circuit type can be understood by a mathematical function shown in Figure 6(b). Figure 6(c) shows the modulation of a signal monitored from a resistor of $1 \mathrm{k} \Omega$, when a full-rectified signal of amplitude $10 \mathrm{~V}$ and frequency of $120 \mathrm{~Hz}$ in GF1 layer, as well as square signal of amplitude $1 \mathrm{~V}$, frequency of $600 \mathrm{~Hz}$, and duty cycle of $50 \%$ in GF3 layer, has been applied. For example, GF1 has lower conductivity and GF3 higher conductivity; the modulation process can be developed.

To validate the technological importance of the green engineering based on graphite circuits it is explained to compare the physical properties such as $\mu_{n}$ and thermal conductivity of graphite samples with those of GaN and silicon. For GaN the degradation of the heat conduction properties depends on quality, purity, and thickness of its films, because lower thermal conductivity of $\mathrm{GaN}$ is in the range of 125 to $225 \mathrm{Wm} / \mathrm{K}$, compared to that of bulk graphite $(k=$ $2000 \mathrm{Wm} / \mathrm{K}$ ) at room temperature [13]. Also, the current conduction of silicon devices has been determined by $\mu_{n}$ in the range of 200 to $1000 \mathrm{~cm}^{2} / \mathrm{Vs}$, which is dependent on the ionized impurity concentration in the range of $10^{15}$ to $10^{18} \mathrm{~cm}^{-3}$ 


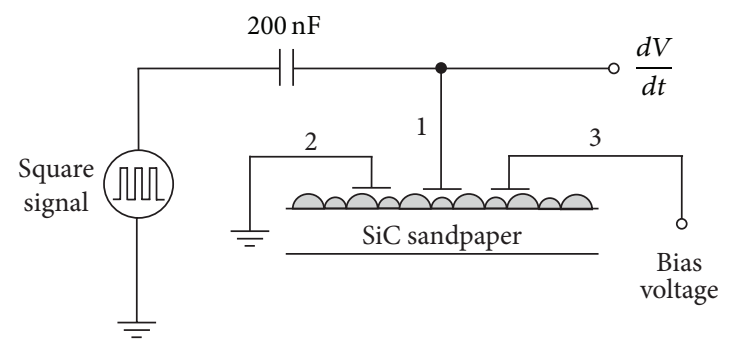

(a)

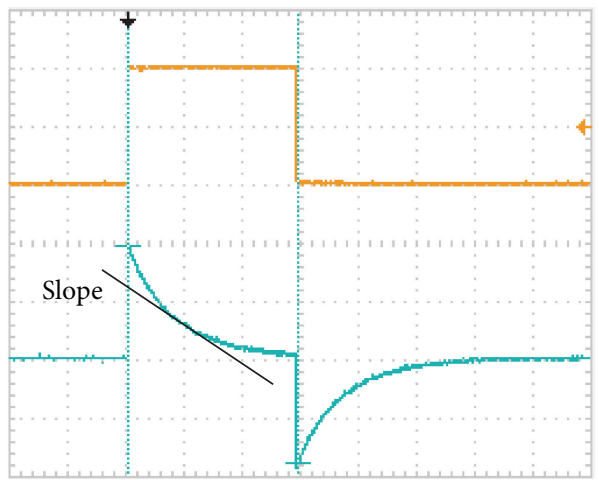

(c)

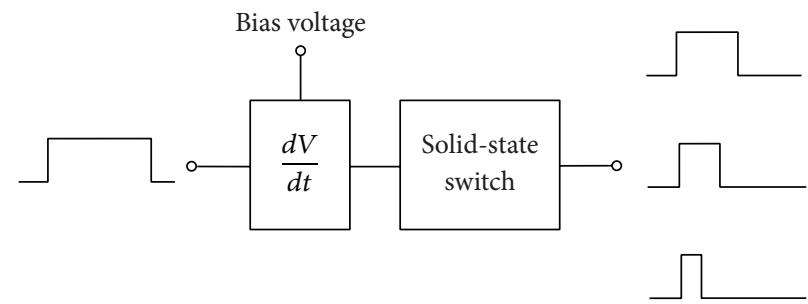

(b)

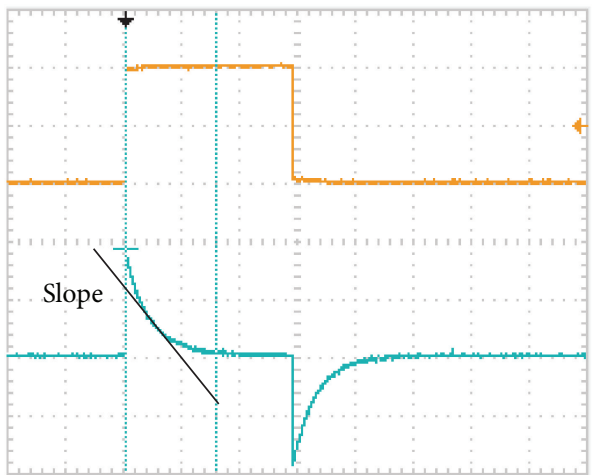

(d)

Figure 5: (a) Practical circuit implemented for derivative of a signal. (b) Block diagram to realization of a PWM circuit based on graphite architectures. (c) Derivative of a signal without bias voltage. (d) Derivative of a signal with bias voltage.

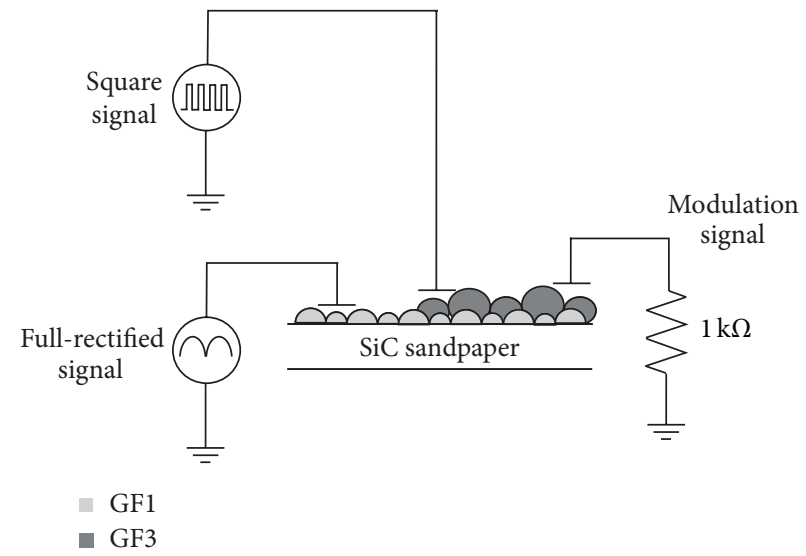

(a)

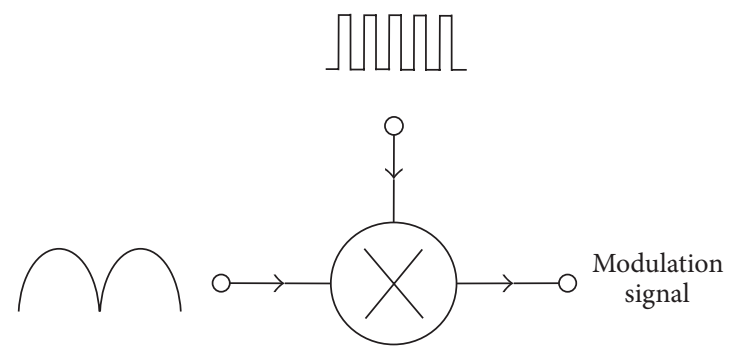

(b)

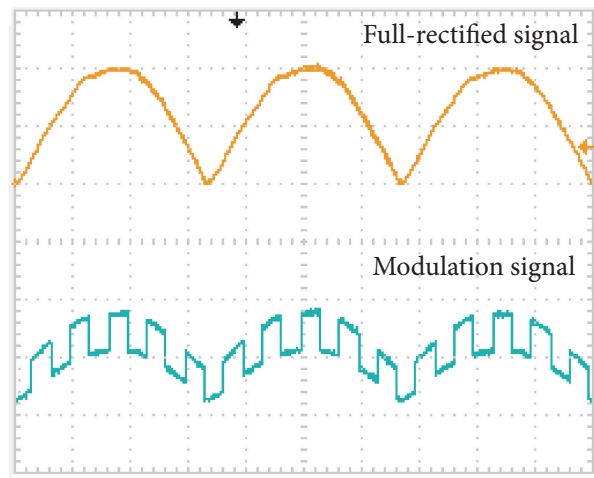

(c)

FIGURE 6: (a) Practical circuit implemented for modulation of a signal. (b) Mathematical function of a modulation process. (c) Modulation of a signal when a full-rectified signal was applied. 
thermally diffused by planar technology at high temperatures [22].

The proposed graphite devices can become an industrialscale alternative for electronic engineering applications; because of that graphite circuits have been built with higher junction area around $\sim 10^{-1} \mathrm{~cm}^{2}$ than that of $10^{-4}$ to $10^{-3} \mathrm{~cm}^{2}$ for silicon and $\mathrm{GaN}$, which allows the fact that heat spreading along graphite layers can be dissipated on $\mathrm{SiC}$ sandpaper when higher current conduction in samples of lower thickness than that of $500 \mathrm{~nm}$ is attained at $\mu_{n}$ in the range of 250 to $290 \mathrm{~cm}^{2} /$ Vs without concentration of donor and acceptor impurities as in silicon devices $[18,22]$, which means that stacking profile of graphite assembled on $\mathrm{SiC}$ sandpaper is associated with lower trap concentration (intrinsic structural defects).

\section{Conclusions}

Graphite layers synthesized by noncontaminant reverse abrasion have been studied. From graphite rods recuperated by old pencils and $\mathrm{SiC}$ sandpaper as an insulating substrate, graphite circuits as an example of green engineering were demonstrated. In spite of graphite limitations as its ambipolar character, design of the graphite-based devices inspired by using different performance principles should be continued in the future. To get stable devices environmentally friendly, automation must be projected for mass production free of toxic sources.

\section{Competing Interests}

The author declares that there are no competing interests, but there is a direct interest regarding the publication of this paper: sharing knowledge about green materials and their applications.

\section{Acknowledgments}

The collected characterization data of XRD and AFM in this work have been possible thanks to the support of Dr. José Alberto Andraca and Dr. Juan Vicente Méndez from CNMN belonging to the National Polytechnic Institute, Mexico City.

\section{References}

[1] F.-L. Luo, W. Williams, R. M. Rao, R. Narasimha, and M. J. Montpetit, "Trends in signal processing applications and industry technology," IEEE Signal Processing Magazine, vol. 12, pp. 171-174, 2012.

[2] T. R. Dickson, Understanding Chemistry from Atoms to Attitudes, LIMUSA, Mexico City, Mexico; John Wiley \& Sons, New York, NY, USA, 1st edition, 2006.

[3] R. Baca-Arroyo, "Nonlinear-electronic transport in $\mathrm{Fe}_{2} \mathrm{O}_{3}$ thinfilms grown from grain-oriented iron foils," Advances in Materials Science and Engineering, vol. 2013, Article ID 987572, 8 pages, 2013.

[4] R. Baca, "Manganese oxide thin-films for current-signal sensing and thermal insulation," Materials Science in Semiconductor Processing, vol. 16, no. 5, pp. 1280-1284, 2013.
[5] R. Baca, "Reliable energy strategy based on incandescent lighting," Energy and Power Engineering, vol. 7, no. 5, pp. 174-180, 2015.

[6] K. E. Whitener Jr. and P. E. Sheehan, "Graphene synthesis," Diamond \& Related Materials, vol. 46, pp. 25-34, 2014.

[7] V. Singh, D. Joung, L. Zhai, S. Das, S. I. Khondaker, and S. Seal, "Graphene based materials: past, present and future," Progress in Materials Science, vol. 56, no. 8, pp. 1178-1271, 2011.

[8] W. Soon, S. L. Baliunas, A. B. Robinson, and Z. W. Robinson, "Environmental effects of increased atmospheric carbon dioxide," Climate Research, vol. 13, no. 2, pp. 149-164, 1999.

[9] A. Cotton and G. Wilkinson, Advanced Inorganic Chemistry, John Wiley \& Sons, New York, NY, USA, 4th edition, 2008.

[10] M. Reuter and A. V. Schaik, "Opportunities and limits of recycling: a dynamic-model-based analysis," MRS Bulletin, vol. 37, no. 4, pp. 339-347, 2012.

[11] A. A. Balandin, "Thermal properties of graphene and nanostructured carbon materials," Nature Materials, vol. 10, no. 8, pp. 569-581, 2011.

[12] L. A. Pendrys, C. Zeller, and F. L. Vogel, "Electrical transport properties of natural and synthetic graphite," Journal of Materials Science, vol. 15, no. 8, pp. 2103-2112, 1980.

[13] Z. Yan, G. Liu, J. M. Khan, and A. A. Balandin, "Graphene quilts for thermal management of high-power GaN transistors," Nature Communications, vol. 3, article 827, 2012.

[14] D. V. De Pellegrin and G. W. Stachowiak, "Sharpness of abrasive particles and surfaces," Wear, vol. 256, no. 6, pp. 614-622, 2004.

[15] G. Venugopal, K. Krishnamoorthy, and S.-J. Kim, "An investigation on high-temperature electrical transport properties of graphene-oxide nano-thinfilms," Applied Surface Science, vol. 280, pp. 903-908, 2013.

[16] C. Xiu-Yun, "Graphene-like nanosheets synthesized by natural flaky graphite in Shandong, China," International Nano Letters, pp. 3-6, 2013.

[17] V. K. Jain, "Magnetic field assisted abrasive based micro-/nanofinishing," Journal of Materials Processing Technology, vol. 209, no. 20, pp. 6022-6038, 2009.

[18] M. Lundstrom, Fundamentals of Carrier Transport, Cambridge University Press, New York, NY, USA, 2nd edition, 2000.

[19] A. S. Sedra and K. C. Smith, Microelectronics Circuits, Oxford University in Press, New York, NY, USA, 4th edition, 1988.

[20] M. H. Rashid, Power Electronics Circuits, Devices, and Applications, Prentice Hall Inc, New York, NY, USA, 1st edition, 1995.

[21] L. Dulau, S. Pontarollo, A. Boimond, J.-F. Garnier, N. Giraudo, and O. Terrasse, "A new gate driver integrated circuit for IGBT devices with advanced protections," IEEE Transactions on Power Electronics, vol. 21, no. 1, pp. 38-43, 2006.

[22] A. S. Grove, Physics and Technology of Semiconductor Devices, John Wiley \& Sons, New York, NY, USA, 1st edition, 1967. 

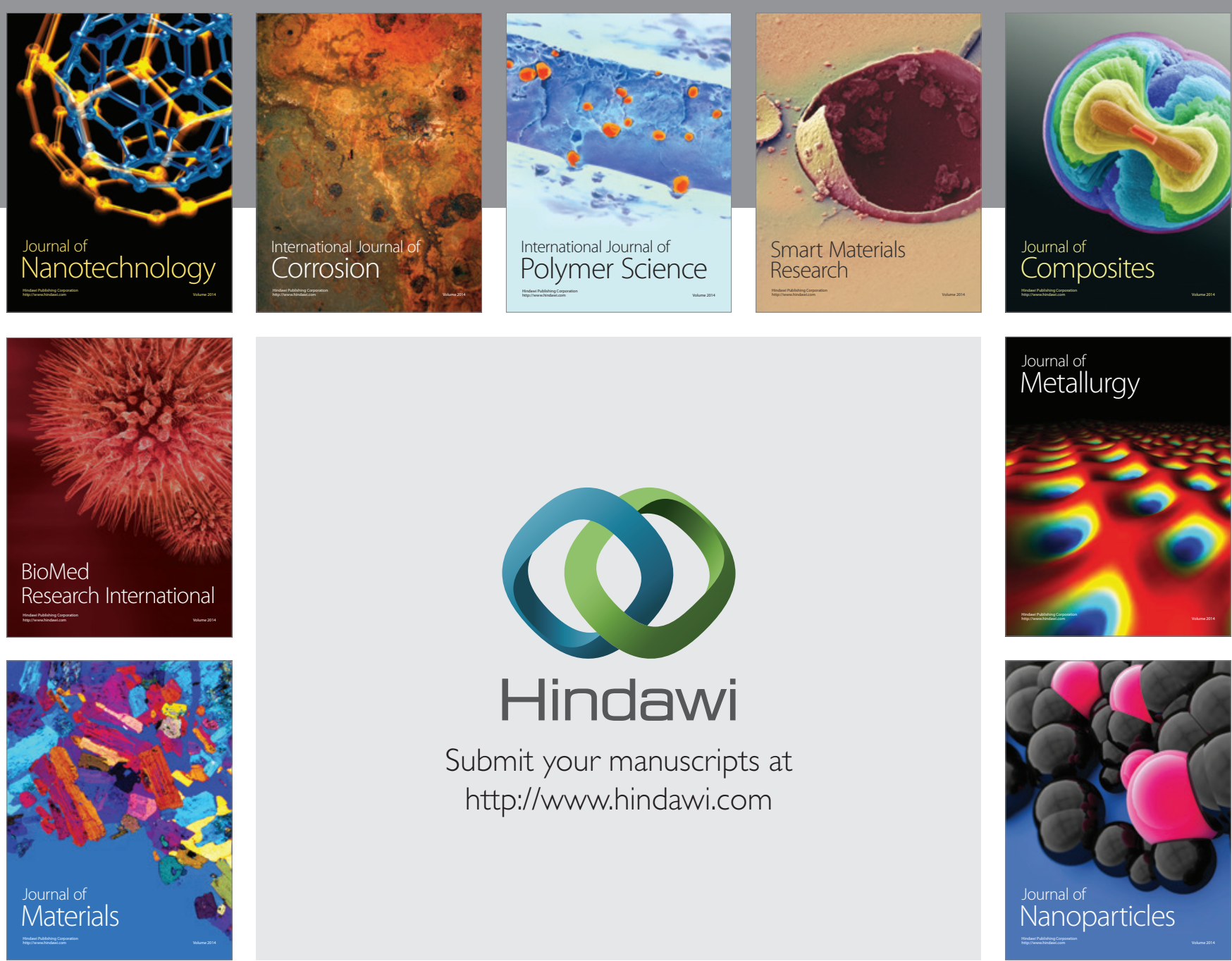

\section{Hindawi}

Submit your manuscripts at

http://www.hindawi.com

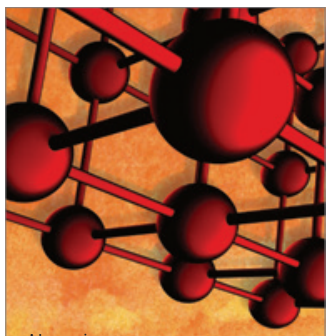

Materials Science and Engineering
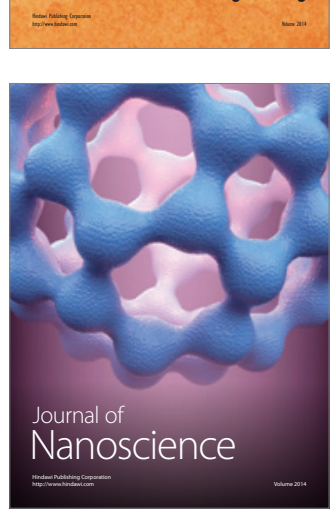
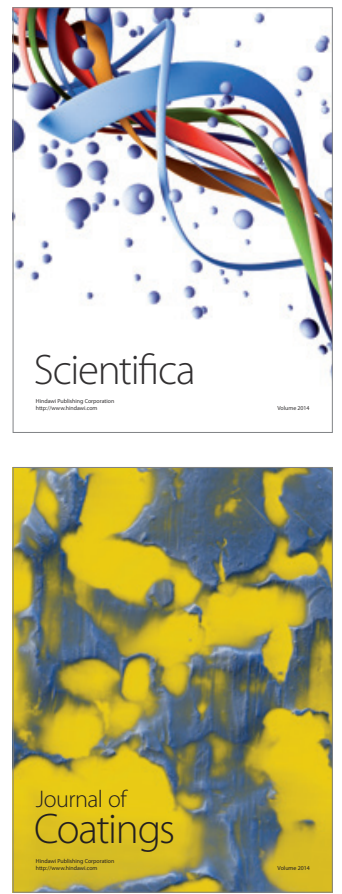
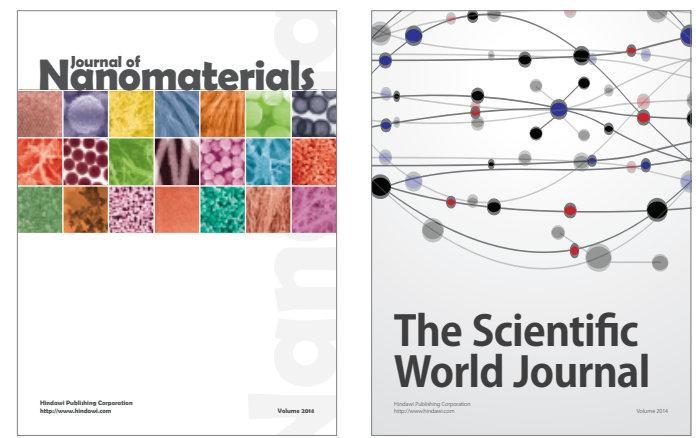

The Scientific World Journal
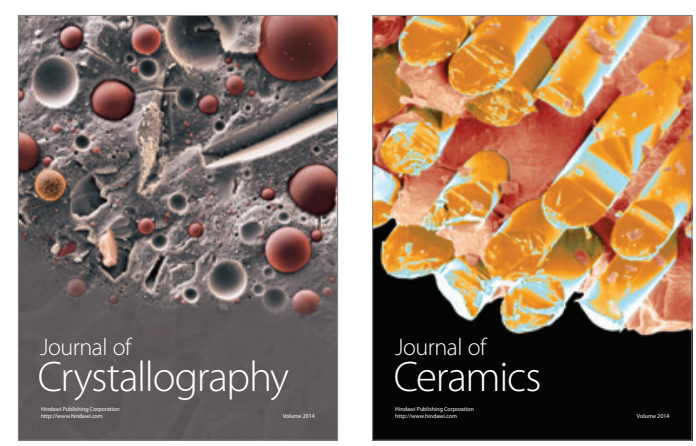
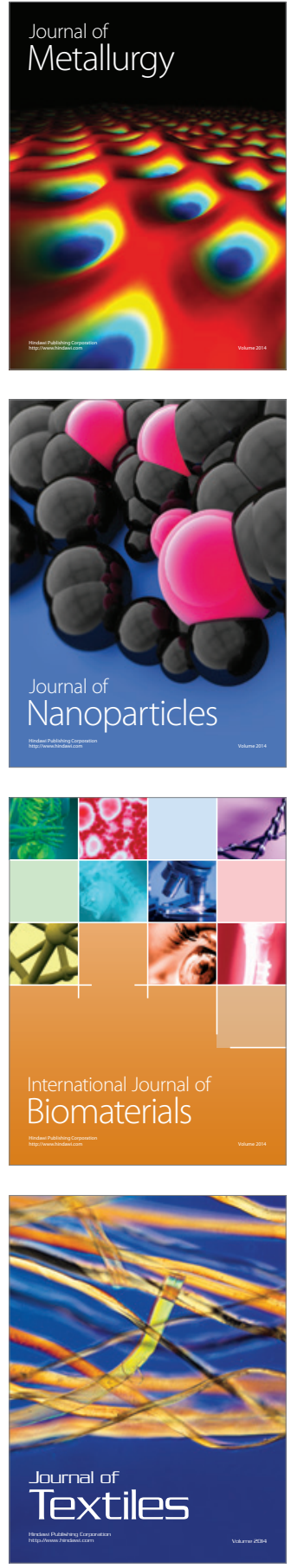